\title{
Reducing noise influence on an audio frequency track circuit
}

\author{
Inna Saiapina ${ }^{1, *}$, Mykhailo Babaiev², and Olha Ananieva ${ }^{3}$ \\ ${ }^{1}$ State University of Infrastructure and Technologies, Telecommunication Technologies and Automation Department, 9 Kyrylivska \\ str., 04071, Kyiv, Ukraine \\ ${ }^{2}$ Ukrainian State University of Railway Transport, Department of electroenergy, electrical equipment and electromecanics, 7 \\ Feierbakh sq., 61050 Kharkiv, Ukraine \\ ${ }^{3}$ Ukrainian State University of Railway Transport, Department of automation and computer telecontrol train traffic, 7 Feierbakh sq., \\ 61050 Kharkiv, Ukraine
}

\begin{abstract}
In connection with electromagnetic interference influence on the track circuits, the purpose of the research is finding the means to increase the noise immunity of an audio frequency track circuit. The authors propose a new engineering solution, which enables reducing the effect of noises on the input of the track receiver in the intervals between signal current pulses. The proposed noise-immune audio frequency track circuit is based on inserting a delay line, an adjustable single-pulse generator and a controlled electronic switch into the existing audio frequency track circuit equipment. To analyze its efficiency, the operation of the audio frequency track circuit was simulated under conditions of traction current disturbances, impulse and fluctuation interferences with the known parameters. The results show that proposed device for railway transport allows to increase a signal-to-noise ratio on the track receiver input from $8 \%$ to $30 \%$, depending on the interference parameters and the level of the useful signal.
\end{abstract}

\section{Introduction}

Track circuits belong to the most popular systems to provide information on position and movements of trains and ensure safety of the railway transportation process $[1,2]$. They are the main track sensors at the Ukrainian railways, and the correct operation of the automatic blocking, dispatching centralization and automatic locomotive signalling systems, and, consequently, the safety of train traffic depends on their functioning.

Audio frequency track circuits are a perspective type of the track circuits due to a number of advantages: absence of block joints, which are one of the most unreliable elements of the track circuits; elimination of the need to install impedance bonds; the possibility of power supply to two adjacent track circuits from one common source, etc [3 - 5]. Railways of Ukraine are equipped with audio frequency (or also called tonal) track circuits of the following modifications: TRC 3 and TRC 4. TRC 3 has the following signal carrier frequencies: $420,480,580,720$ and $780 \mathrm{~Hz}$. In the TRC 4 carrier frequencies are 4500,5000 and $5500 \mathrm{~Hz}$. The power to audio frequency track circuits is supplied by an AM tone signal. However, the operating conditions of audio frequency track circuits are characterized by the impact of a variety of different interferences (Figure 1) [6-12].

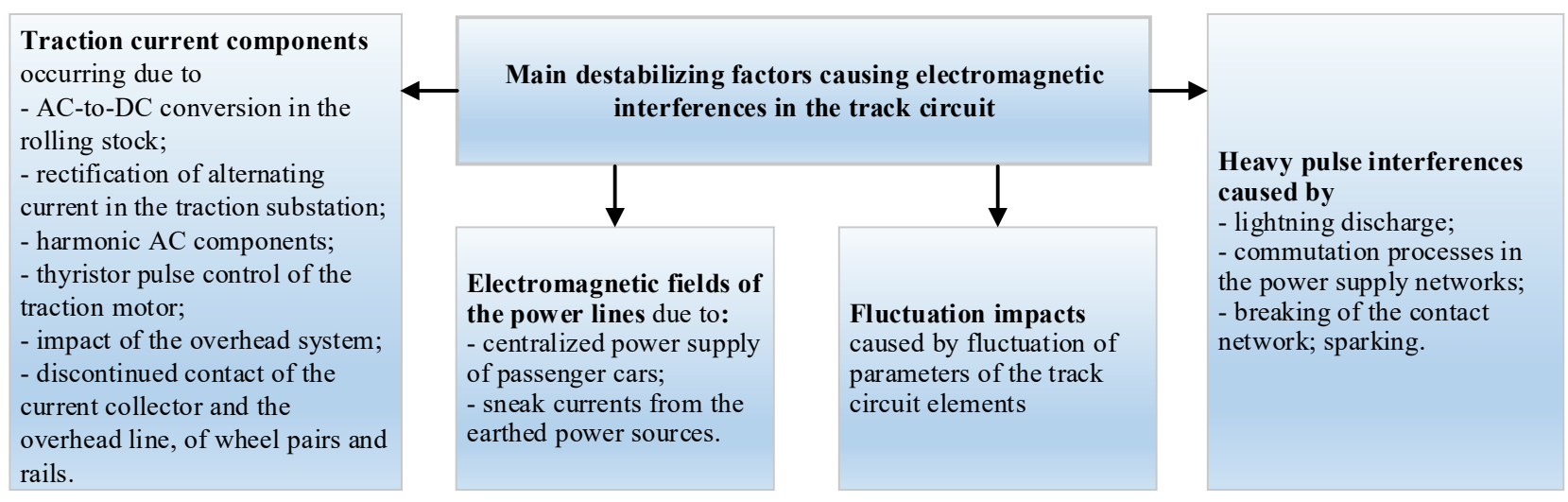

Fig. 1. Main factors causing interferences in track circuits

\footnotetext{
*orresponding author: inna.saiapina@gmail.com
} 
Materials $[13,14]$ show that the most industrial and atmospheric disturbances are characterized by a rapid change in the electric current causing occurrence of electric and magnetic fields that interfere with the reception of a useful signal in the track circuits. The highest levels of impulse noise occur during switching, accompanied by a short circuit or a circuit interruption. When the alternating current passes the circuit with a nonlinear resistance, interferences from harmonic and combinational components of the fundamental frequency appear.

In [15] it is mentioned that in the range of low values, fluctuations of the ballast resistance have significant impact on the input voltage of the track receiver, which can cause a malfunction of the tone track circuit due to fluctuation interferences.

Interference caused by the operation of asynchronous traction motors with impulse control, which most new types of electric rolling stock are equipped with, is particularly dangerous for the operation of audio frequency track circuits. Their operation causes broadband electrical noise in the reverse traction current circuit, which are within the operating frequency range of these track circuits [16-19].

Papers [20, 21] consider the methods of protection of railway automation systems against over-voltage, describe the effect of traction current on jointless track circuits and ways of protecting against it. In work [21], a study of increasing the noise immunity of a track receiver (TR) by using various methods of modulation and demodulation of the rail control signal was performed.

However, these existing methods of increasing noise immunity cannot completely prevent the effect of interference on the receiving equipment of the track circuits which require further improvement. Authors propose an engineering solution to improve noise immunity, which will reduce the time of interference effects on the track receiver of audio frequency track circuits $[22,23]$. To study its efficiency, the operation of audio frequency track circuits when exposed to different interferences was simulated.

\section{Solutions to improve the noise immunity of the track circuits}

An engineering solution [23] to improve the noise immunity of audio frequency track circuits has been developed to reduce the effect of interference at the input of the track receiver in the intervals between the status monitoring signal pulses of the audio frequency track circuits. To construct the proposed noise-immune audio frequency track circuit the following new elements have been further introduced into the established audio frequency track circuit equipment: an adjustable delay line (DL), single pulse generator (SPG) and managed electronic switch (ES) (marked with yellow color on Figure 2).

The principle of operation involved opening the controlled electronic switch at the input of the track receiver in the absence of a useful signal. The effect of interference is reduced due to the implementation of guard intervals in the pauses between the useful signal pulses, during which the interference from the transmission channel of audio frequency track circuits cannot reach the input of the track receiver.

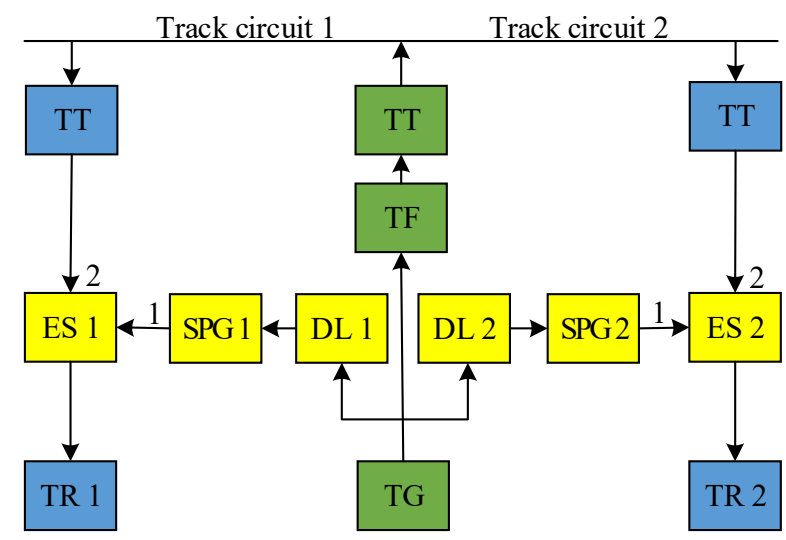

Fig. 2. Block diagram of noise-immune audio frequency track circuit

Moreover, the length of the pulse generated by the single-pulse generator and thus the length of the guard interval can be adjusted.

This device is intended for use in systems with centralized equipment arrangement. The block diagram (Figure 2) shows the feeding end of the track circuit, which includes a track generator (TG), a track filter (TF), a track transformer (TT) and two relay ends of adjacent rail circuits consisting of a track relay (TR) and a track transformer (TT). The model of the device was developed in SIMULINK $®$ software (Figure 3)

The generator block consists of three functional blocks: a carrier frequency generator, a pulse generator and a modulator. The carrier frequency generator produces a sinusoidal signal of a specified frequency and amplitude, which is fed to the first input of the modulator. The second input of the modulator is supplied with a pulse signal with a modulation frequency. The modulator performs the operation of multiplying a sinusoidal signal of the carrier frequency with a pulse signal, which has a modulation frequency. The form of the signal on the output of the track generator block is shown on Figure 4a. The track filter block is modelled on the basis of capacitive, active and reactive resistance elements. The cable link line, as well as the rail line, is made in the model using the Simulink 'Transmission Line' block. The model type in the block options is chosen as 'Line with distributed parameters', its primary parameters and length are specified. The track transformer block consists of a transformer with a transform coefficient of 38 , which is connected through a protective resistor. The input resistance of the adjacent sections of the rail line from both the supply and the relay end is taken into account by the inclusion of the corresponding complex resistances shown in Figure 3 as 'Adjacent rail line' blocks.

The experimental setup for the modelling was as follows: frequency from the carrier frequency generator - from 420 to $780 \mathrm{~Hz}$; modulation frequency of the pulse 
generator - from 8 or $12 \mathrm{~Hz}$; output signal voltage of the track generator block - from 1 to $8 \mathrm{~V}$; specific active resistance of the rail line - from 0.935 to $1.24 \mathrm{Ohm} / \mathrm{km}$; specific inductance of the rail line - from 1.59 to 1.82
$\mathrm{mH}$; insulation resistance of the rail line - from 0.5 to 50 $\mathrm{Ohm} / \mathrm{km}$; length of the cable link line - from 0 to $6 \mathrm{~km}$; length of the rail line - from 50 to $1100 \mathrm{~m}$.

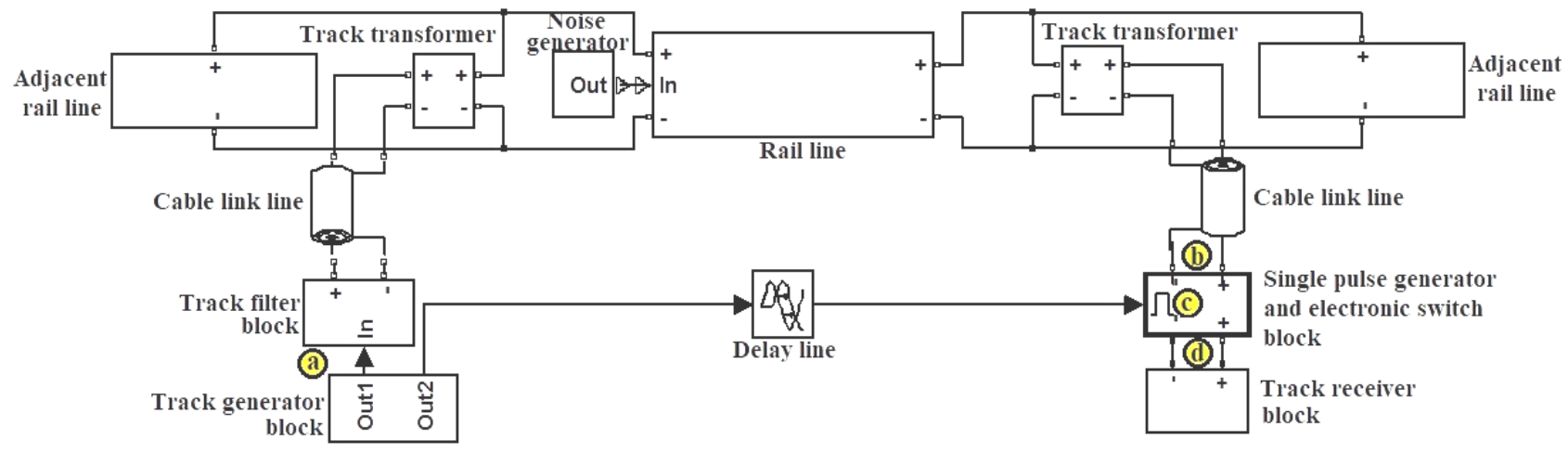

Fig. 3. Simulink model of the proposed device

To check the adequacy of the model, the sampling of voltage values on track circuit elements in the model was compared to the voltage values on the real track circuit using the following criteria of mathematical statistics: the Mann-Whitney criterion, the Fisher criterion, the Student's test. The results confirmed the adequacy of the model with the confidence probability of $95 \%$ [22].

Since one generator encodes the track circuit and the delay line (Figure 3), the generated signal (Figure 4a) simultaneously arrives at 2 inputs: the track filter input and the delay line.
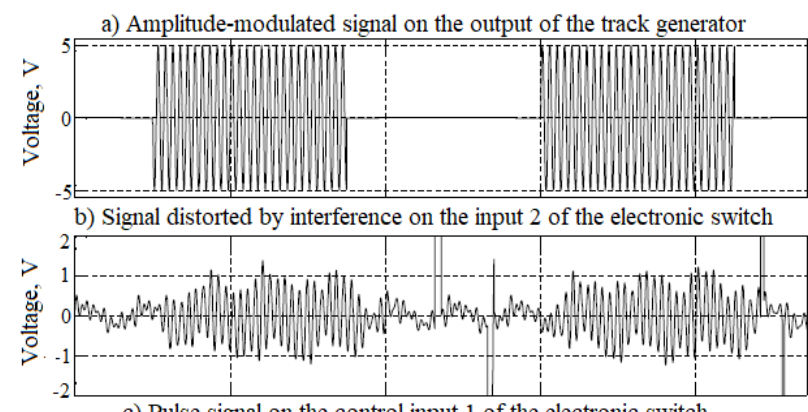

c) Pulse signal on the control input 1 of the electronic switch
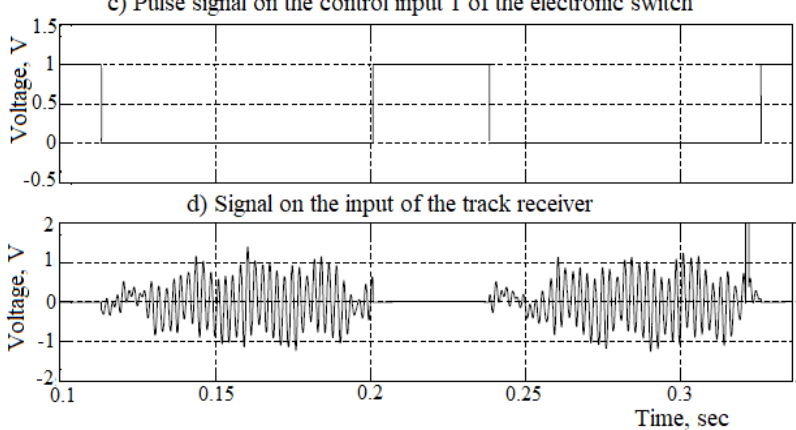

Fig. 4. Signal forms on the elements of the proposed device in the Simulink model

From the track filter through the track transformer, the signal enters the track circuit. If it is free, the signal together with the track circuit interference (Figure 4b) passes through the track transformer to the input 2 (Figure 2) or input, matched 'b' (Figure 3), of the electronic switch.
The delay line is designed for the time of passage of the useful signal from track generator to the input 2 of the electronic switch in the audio frequency track circuits. As the signal from the delay line arrives at the input of a single pulse generator, it generates a single pulse (Figure 4c). When the pulse appears on the control input 1, the electronic switch interrupts the circuit; as a result, interference from input 2 of the electronic switch cannot reach the input of the track receiver during the pulse signal (Figure 3d). Thus, the possibility of interference to the track receiver within the guard interval between the status monitoring signal pulses of the audio frequency track circuits is excluded.

\section{Efficiency analysis of the proposed solution}

To analyze the efficiency of the proposed engineering solution, the effect of the interference from traction current, as well as impulse and fluctuation interference on the operation of the audio frequency track circuit was simulated using SIMULINK ${ }^{\circledR}$ model (Figure 3).

For this purpose, the noise generator block of the model synthesizes interference, which includes impulse interference, fluctuation interference and a harmonic signal from traction current disturbances: interference from a direct traction current, interference from alternating traction current and interference from direct traction current and thyristor engine control. The nature of the effect of interference from the traction current depends on their harmonic composition, which is determined by the harmonic coefficient.

The interference from a direct traction current according to [5] consists of three main harmonics: the one with the frequency of $50 \mathrm{~Hz}$ has harmonic content factor 0.072; the one with the frequency of $200 \mathrm{~Hz}$ has harmonic content factor 0.013 and the one with the frequency of $300 \mathrm{~Hz}$ has harmonic content factor 0.017 .

The interference from an alternating traction current according to [5] consists of odd harmonics, shown in Table 1 . 
Table 1. Harmonic components of alternating traction current in the rail line

\begin{tabular}{|c|c|c|c|c|c|}
\hline $\begin{array}{c}\text { The har- } \\
\text { monic } \\
\text { order }\end{array}$ & $\begin{array}{c}\text { Fre- } \\
\text { quen- } \\
\text { cy, Hz }\end{array}$ & $\begin{array}{c}\text { percentage of } \\
\text { harmonic } \\
\text { content, \% }\end{array}$ & $\begin{array}{c}\text { The } \\
\text { har- } \\
\text { monic } \\
\text { order }\end{array}$ & $\begin{array}{c}\text { Fre- } \\
\text { quen- } \\
\text { cy, Hz }\end{array}$ & $\begin{array}{c}\text { The } \\
\text { percentage of } \\
\text { harmonic } \\
\text { content, \% }\end{array}$ \\
\hline 3 & 150 & 30 & 19 & 950 & 0,11 \\
\hline 4 & 200 & 0,3 & 21 & 1050 & 0,07 \\
\hline 5 & 250 & 15 & 23 & 1150 & 0,10 \\
\hline 6 & 300 & 0,1 & 25 & 1250 & 0,09 \\
\hline 7 & 350 & 5 & 27 & 1350 & 0,09 \\
\hline 8 & 400 & 0,05 & 29 & 1450 & 0,2 \\
\hline 9 & 450 & 2 & 31 & 1550 & 0,04 \\
\hline 11 & 550 & 1,5 & 33 & 1650 & 0,2 \\
\hline 13 & 650 & 1,2 & 35 & 1750 & 0,2 \\
\hline 15 & 750 & 0,8 & 37 & 1850 & 0,1 \\
\hline 17 & 850 & 0,5 & 39 & 1950 & 0,1 \\
\hline
\end{tabular}

The interference from direct traction current and thyristor engine control according to [5] consists of currents with certain frequencies and peak amplitudes shown in Table 2.

Table 2. Maximum currents of interference in the rail line during operation of thyristor converters

\begin{tabular}{|c|c|c|c|c|c|c|c|c|c|}
\hline $\begin{array}{c}\text { Frequency, } \\
\text { Hz }\end{array}$ & 25 & 50 & 75 & 125 & 175 & 225 & 275 & 325 & 375 \\
\hline $\begin{array}{c}\text { Amplitude, } \\
\text { A }\end{array}$ & 4,7 & 1,1 & 6,2 & 3,8 & 2,6 & 2,0 & 3,4 & 2,6 & 2,2 \\
\hline
\end{tabular}

Pulse noises in track circuits are usually caused by lightning discharges, emergency and switching processes in power supply systems. To simulate the effect of pulse interference on the track circuit, a random pulse sequence model is used which was obtained in [7] as a result of recording the interferences in the railway. According to it, the amplitude of pulses is within the range from -47 to $51 \mathrm{~V}$. Mathematical expectation for the pulse duration is $3.52 \mathrm{~ms}$, the dispersion is 17.01 $\mathrm{ms}^{2}$, the mean square deviation is $4.12 \mathrm{~ms}$. For interpulse intervals, the mathematical expectation is 171.7 $\mathrm{ms}$, the dispersion is $0.2030 \mathrm{~s}^{2}$ and the mean square deviation is $0.451 \mathrm{~s}$. The duration of the interference is

$$
\omega_{\text {imp }}(n)=\lambda e^{-\lambda n}
$$

where $\lambda=284,057$, while duration of inter-pulse intervals according to the maximum likelihood criterion of the is subject to the gamma distribution

$$
w_{\text {int }}(n)=\frac{b^{a}}{\Gamma(\mathrm{a})} n^{a-1} e^{-b n},
$$

where $\quad \Gamma(x)=\int_{0}^{\infty} z^{x-1} e^{-z} d z \quad$ - gamma function with parameters $\mathrm{a}=0.0109$ and $\mathrm{b}=1.216$.

An example of implementation of the described pulse interference is shown in Fig. 5.

Fluctuation interference can be characterized as a continuous process, consisting of multiple pulses with random amplitude. The main cause of the fluctuation interferences in the track circuit is its own noises caused by the fluctuation of parameters of its elements, as well as other noise of the surrounding space.

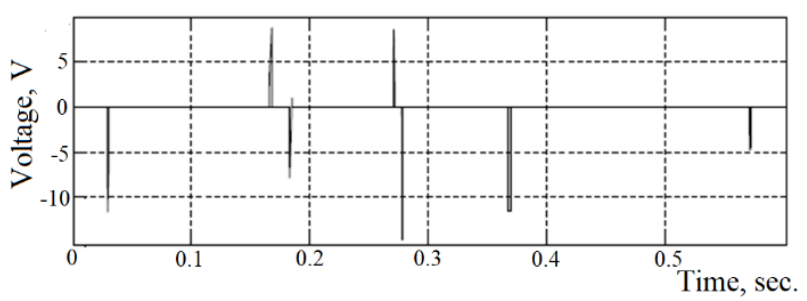

Fig. 5. An example of pulse interference on the track receiver input

The model of fluctuation interference affecting the track circuit is a white Gaussian noise with the indicated values of interference characteristics: zero mathematical expectation and unit dispersion. An example of implementation of fluctuation interference is shown in Fig. 6.

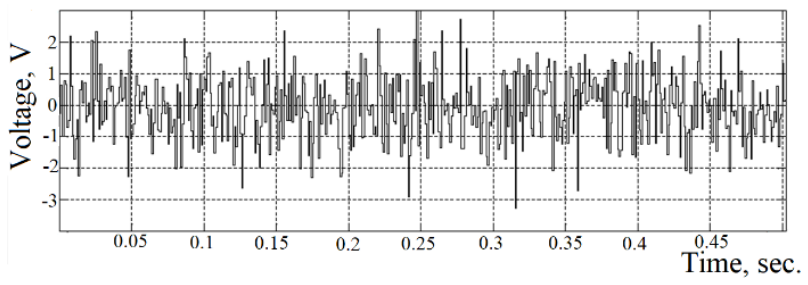

Fig. 6. An example of fluctuation interference on the track receiver input

To estimate the increase in noise immunity with the proposed engineering solution, the signal-to-noise ratio (SNR) (3) at the input of the track receiver has been calculated using the device when exposed to the described interference on the transmission path, and without using it. The voltage signals $U_{\text {signal }}$ and $U_{\text {interference }}$ on the input of the track receiver (point 'd' in Figure 3) were measured using the Simulink model. Expressions (4) and (5) allow to determine signal and interference power.

$$
\begin{gathered}
S N R_{d B}=10 \cdot \lg \left(\frac{P_{\text {signal }}}{P_{\text {interference }}}\right) \\
P_{\text {signal }}=\frac{1}{T} \int_{-\frac{T}{2}}^{\frac{T}{2}} U_{\text {signal }}^{2}(t) d t \\
P_{\text {interference }}=\frac{1}{\tau} \int_{0}^{\tau} U_{\text {interference }}^{2}(t) d t
\end{gathered}
$$

where $S N R_{d B}$ is a signal-to-noise ratio, calculated in $\mathrm{dB}$; $P_{\text {signal }}$ is the average power dissipated by the signal during the time interval; $T$ is a signal period; $U_{\text {signal }}(t)$ is the useful signal; $P_{\text {interference }}$ is the average power dissipated by the interference signal; $\tau$ is a time interval; $U_{\text {interference }}$ is a voltage of an interference signal. 
Based on expressions (3-5) using Mathcad $\AA$ software, comparative signal-to-noise ratios have been obtained when exposed to interference from traction current in the sections with DC and AC electrification, as well as interference from thyristor control of the traction motor, impulse interference and fluctuation interference. The simulation results are shown in Tables 3 and 4.

Table 3. Signal/noise ratio when exposed to interference from traction current.

\begin{tabular}{|l|c|c|c|c|c|c|}
\hline & \multicolumn{2}{|c|}{$\begin{array}{c}S N R \text { when the device for } \\
\text { increasing noise immunity is } \\
\text { not used, dB }\end{array}$} & $\begin{array}{c}S N R \text { when the device for } \\
\text { increasing noise immunity is } \\
\text { used, dB }\end{array}$ & $\begin{array}{c}\% \text { increase in SNR due to the } \\
\text { use of device for increasing } \\
\text { noise immunity }\end{array}$ \\
\cline { 2 - 7 } & $U_{s I}=1,2 \mathrm{~V}$ & $U_{s 2}=1,5 \mathrm{~V}$ & $U_{s I}=1,2 \mathrm{~V}$ & $U_{s 2}=1,5 \mathrm{~V}$ & $U_{s I}=1,2 \mathrm{~V}$ & $U_{s 2}=1,5 \mathrm{~V}$ \\
\hline $\begin{array}{l}\text { When exposed to interference } \\
\text { from a direct traction current }\end{array}$ & 5,269 & 6,852 & 5,982 & 7,566 & $13,5 \%$ & $10,4 \%$ \\
\hline $\begin{array}{l}\text { When exposed to interference } \\
\text { from alternating traction current }\end{array}$ & 2,117 & 3,701 & 2,788 & 4,372 & $30,6 \%$ & $18,1 \%$ \\
\hline $\begin{array}{l}\text { When exposed to interference } \\
\text { from direct traction current and } \\
\text { thyristor engine control }\end{array}$ & 5,084 & 6,668 & 5,965 & 7,549 & $17,3 \%$ & $13,2 \%$ \\
\hline
\end{tabular}

Table 4. Signal/noise ratio when exposed to impulse and fluctuation interference.

\begin{tabular}{|l|c|c|c|}
\hline & $\begin{array}{c}S N R \text { when the device for } \\
\text { increasing noise immunity is } \\
\text { not used, dB }\end{array}$ & $\begin{array}{c}S N R \text { when the device for } \\
\text { increasing noise immunity is } \\
\text { used, dB }\end{array}$ & $\begin{array}{c}\% \text { increase in SNR due to the } \\
\text { use of device for increasing } \\
\text { noise immunity }\end{array}$ \\
\cline { 2 - 4 } & $U_{s l}=1,25 \mathrm{~V}$ & $U_{s I}=1,25 \mathrm{~V}$ & $U_{s I}=1,25 \mathrm{~V}$ \\
\hline $\begin{array}{l}\text { When exposed to impulse } \\
\text { interference }\end{array}$ & 1,13 & 1,39 & $23 \%$ \\
\hline $\begin{array}{l}\text { When exposed to fluctuation } \\
\text { interference }\end{array}$ & 7,97 & 8,64 & $8,4 \%$ \\
\hline
\end{tabular}

The SNR increase percentage at the input of the track receiver is the ratio of SNR obtained when using the device for improving noise immunity to SNR obtained without using it, and is expressed as a percentage, at the corresponding useful signal voltage $U_{s}$ on the input of the track receiver.

\section{Conclusions}

This article proposes a device for improving noise immunity of an audio frequency track circuit with the centralized equipment arrangement, which contributes to reduction of the effect of interference on the input of the track receiver in the intervals between the signal current pulses. The reliability of the railway automatics systems which are responsible for the safety of the transportation process depends on the noise immunity of the track circuit. That is, the proposed solution can improve the safety of trains. Noise immunity of the audio frequency track circuit is improved due to the introduction of a delay line, an adjustable single pulse generator and a controlled electronic switch. The device work is based on cutting the interference in the interval between the useful signal pulses. In order to evaluate how effective the proposed engineering solution increases the noise immunity, the operation of the audio frequency track circuit affected by interferences from traction current, thyristor control, pulse and fluctuation noise was simulated. A signal/noise ratio (SNR) is obtained at the input of the track receiver both during the normal operation of the audio frequency track circuit and when the proposed device to increase noise immunity is used. On the basis of their comparison, the percentage value (\% increase in SNR) is obtained, which reflects the degree of noise immunity at the input of the track receiver of the audio frequency track circuit. According to the results of the analysis, this degree is from $8 \%$ to $30 \%$, depending on the level of the useful signal and the parameters of the interference.

\section{References}

1. J. Wybo, Track circuit reliability assessment for preventing railway accidents. Safety Science, 118, 268-275 (2018) DOI: https://doi.org/10.1016/j.ssci.2018.03.022

2. T. de Bruin, K. Verbert, R. Babuška, Railway Track Circuit Fault Diagnosis Using Recurrent Neural Networks. IEEE Transactions on Neural Networks and Learning Systems, 28, 523-533 (2017) DOI: https://doi.org/10.1109/TNNLS.2016.2551940

3. V. Havryliuk. Audio Frequency Track Circuits Monitoring Based on Wavelet Transform and Artificial Neural Network Classifier. 2019 IEEE 2nd Ukraine Conference on Electrical and Computer Engineering (UKRCON-2019), 491-496 (2019)

4. Railway Group Standards, "TI.21 Audio Frequency Track Circuits”, GKRC0761 Iss 1Use, Jun 1996.

5. V.S. Arkatov, Yu. V. Arkatov, S.V. Kazeev, Yu. V. Obodovskiy Track circuits of mainline railways. (Moscow, Transport Publ., 2006) (in Russian)

6. A.D. Manakov, V.A. Kudryavtsev, A.T. Os'minin, Methods of determining the interference current in rails of double subway track circuits. Russ. Electr. Engin., 87, 282-285 (2016) (in Russian) DOI: https://doi.org/10.3103/S1068371216050102 
7. K.E. Blachev, Imitating modeling of a digital signal receiver of system of an interval handling of traffic of trains. Vestnik of Samara State Technical University: Technical Sciences Series. 2 (22). 223-227 (2008) (in Russian)

8. K.V. Honcharov Investigation of transient processes in tonal track circuits. Science and Transport Progress. Bulletin of Dnipropetrovsk National University of Railway Transport named after Academician V. Lazaryan, 4 (46), 7-17 (2013) (in Russian)

DOI: https://doi.org/10.15802/stp2013/16567

9. Serdyuk T.N., Zavgorodniy A.V., Gavrilyuk V.I. Measurement of electromagnetic interference in the return traction network. Bulletin of Dnipropetrovsk National University of Railway Transport named after Academician V. Lazaryan, 29, 134-139 (2009). (in Russian) DOI: https://doi.org/10.15802/stp2015/55352

10. Standard EN 50121. Railway applications. Electromagnetic compatibility. (London : BSI, 2015) DOI: https://doi.org/10.3403/BSEN50121

11. K.V. Honcharov Methods of protection of tonal track circuits from influence of pulse interferences. Bulletin of DNURT named after Academician V. Lazaryan, 38, 188-193 (2011).

12. I. O. Saiapina. Analysis of an electromagnetic interference impact on the tonal track circuit's receiving equipment. Information-operating system on railway transport, 3, 24-31 (2013) (in Russian)

13. T. N. Serdiuk, V Gavrilyuk. Interaction of electrosupply traction system of direct current with the rail circuits. Information-operating system on railway transport, 4, 108-112, (2007) (in Russian)

14. V. I. Shcheka. The organization of rail circuits protection from electromagnetic interference from the contact network's side. Electromagnetic compatibility and safety on railway transport, 1, 8490, (2011) (in Ukrainian) DOI: https://doi.org/10.15802/ecsrt2011/35202

$15 . \mathrm{K} . \mathrm{V}$ Honcharov. Improving the stability of tonal track circuits under fluctuations of ballast resistance. Science and Transport Progress. Bulletin of Dnipropetrovsk National University of Railway Transport, 6(48), 23-31 (2013) (in Russian) DOI: https://doi.org/10.15802/stp2013/19674
16. V.I. Havryliuk. Modelling of the return traction current harmonics distribution in rails for $\mathrm{AC}$ electric railway system. 2018 International Symposium on Electromagnetic Compatibility (EMC EUROPE). IEEE, 251-254 (2018) DOI: https://doi.org/10.1109/EMCEurope.2018.8485160

17. V. I. Shcheka. Mathematical modelling of track circuits' protection system from electromagnetic disturbances. Electromagnetic compatibility and safety on railway transport, 12, 33-40 (2016) (in Ukrainian)

DOI: https://doi.org/10.15802/ecsrt2016/105492

18. A. M. Beznaritnyy, V. I. Gavrilyuk, I. O. Romantsyev, V. I. Shcheka. Electromagnetic compatibility research of return traction network with signaling devices, centralization and blocking. Science and Transport Progress. Bulletin of Dnipropetrovsk National University of Railway Transport, 3(51), 7-14 (2014) (in Russian) DOI: https://doi.org/10.15802/stp2014/25778

19. V. I. Havryliuk, V. I. Shcheka, V. V. Meleshko. Tests of new types of rolling stock on electromagnetic compatibility with signaling and communication devices. Science and Transport Progress. Bulletin of Dnipropetrovsk National University of Railway Transport, 5 (59), 7-15 (2015) (in Russian) DOI: https://doi.org/10.15802/stp2015/55352

20. A. A. Antonov, P. E. Maschenko., A.S. Shapovalova. Effect of Tractive Current on Long-welded Track Circuits. World of transport and transportation, 1, 46-51, (2010) (in Russian)

21. K. V. Honcharov, Comparative analysis of modulation and demodulation methods of the control signals of rail line. Science and transport progress. Bulletin of DNURT named after Academician $V$. Lazaryan, 42, 12-19, (2012) (in Russian)

22. Saiapina, I.O. Improvement of methods and means to increase audio frequency track circuits noise immunity. Thesis of PhD Kharkiv (2017) (in Ukrainian)

23. Babaiev M.M., Koshevyy S.V., Sotnyk V.O., Romanchuk V.B., Ananieva O.M., Saiapina I.O. Track circuit. Patent UA, no. 101093, (2013) (in Ukrainian) 